\title{
AGUAS MEDICINALES DE SAN-LORENZO (TOLIMA)* ESTUDIO PRESENTADO EN EL SEGUNDO CONGRESO MÉDICO NACIONAL
}

\author{
Por el Doctor Adriano Perdomo \\ De Bogotá
}

Elevados ideales científicos y muy altos fines humanitarios y patrióticos se revelan en la escogencia de los temas propuestos por la Junta Organizadora para la discusión de este augusto Congreso.

Nada más importante, por, ejemplo, que el segundo tema de la primera sección: Aguas Minerales de Colombia. Sin embargo, para mí hubiera pasado inadvertido este asunto, dado el deplorable atraso y descuido en que se tienen estos estudios en el país, si una singular simpatía por la hidroterapia no me hubiera llevado a hacer una importante gira de estudios médicos, por las aguas minerales del centro de Francia, poniendo de relieve ante mis ojos su importancia, tanto para la terapéutica como para la riqueza de un país.

Pasmado se queda en realidad quien por primera vez visita esos alcázares de la hidroterapia, que a virtud de las aguas medicinales y mediante el misterioso poder de las Náyades de las fuentes se levantan hoy en Neris, Mont-Dore, La Bourboule, Vichy, etc.

El puesto que ocupan las aguas minerales en la terapéutica no es conquista moderna, en todos esos grandes balnearios han descubierto los arqueólogos las huellas del hombre desde la época neolítica, y mil vestigios de todo género atestiguan con la elocuenciay la grandiosidad de las ruinas antiguas, la prosperidad que alcanzaron algunos de ellos en la época galorromana, y pregonan el favor que han disfrutado las aguas en todo tiempo. En efecto, la vida de las aguas minerales prospera desde hace siglos: el empirismo ha fijado las indicaciones de las fuentes mucho antes que los sabios hayan encontrado una explicación 'razonada, quedando envueltos sus efectos en el misterioso poder de las Naïades.

En este estado de empirismo permaneció la aplicación de las aguas medicinales hasta principios del siglo pasado, llegando el desdén hasta considerar al hidrólogo en un rango muy inferior en la profesión médica.

Químicos y médicos notables como Vauquelin, Bertrand, Durand Fardel y Guber dieron un rumbo científico al estudio y aplicación de las aguas minerales separándose de la tradición fundada en el empirismo.

Los progresos de la química y el perfeccionamiento de los métodos de análisis, gracias a los cuales se ha podido reconocer y dosificar en las aguas minerales la presencia de cuerpos y gases raros, van disipando las sombras misteriosas que han envuelto por tántos siglos la acción de las aguas minerales, dando a la hidrología el rango científico que en justicia merece.

El descubrimiento del radium por Curie y la comprobación que hizo de la presencia en ciertas aguas minerales de las emanaciones de este metal de tan poderosa influencia terapéutica, ha venido a explicarnos las maravillosas propiedades de algunas aguas que, consideradas únicamente desde el punto de vista de

\footnotetext{
* Tomado de la revista Repertorio de Medicina y Cirugia, volumen IV, N I, octubre 15 de 1912 .
} 
su composición química, no deberían poseer ninguna actividad especial.

Consecutivamente Mareu, siguiendo los estudios de Ramsey sobre el argon, el neon, cripton y el helio, descubrió y dosificó en las aguas de algunos manantiales la presencia de estos gases raros, de los cuales el helio es considerado como resultado de transformaciones del radio llegando a la conclusión de que los gases raros del aire procedían, en su mayor parte, de las aguas minerales que muy a menudo los contienen en gran cantidad.

Investigaciones recientes de M. Leduc han demostrado también que ciertas aguas contienen sustancias químicas solubilizadas en forma de iones positivos o negativos, y cuando el cuerpo humano es sumergido en un baño de esta naturaleza, se forman corrientes eléctricas y se producen cambios moleculares entre estos iones de carga eléctrica contraria y las sustancias salinas disueltas en los humores del organismo.

Todos conocemos la importancia terapéutica de las soluciones metálicas al estado coloidal. ¿Por qué no buscar en la acción prodigiosa de ciertas aguas la influencia de estos fermentos metálicos, sabiendo que la naturaleza es el gran laboratorio, que tiene por ingredientes un fondo inagotable de minerales, por agentes todos los fuegos subterráneos y a su disposición la vasta oficina del interior del globo? Con sagacidad de sabio ha emprendido el doctor Gastou, jefe del laboratorio de radiología del hospital San Luis, en asocio del doctor Ferreyrolles, estas importantes investigaciones, llegando a sorprender los misterios coloidales de la fuente Choussy, gracias a las indiscreciones del ultramicroscopio. A nuestro paso por la Bourboule recibimos una lección práctica del doctor Gastou, quien nos mostró al ultra-microscopio los coloidales $y$ cristaloides de la fuente Choussy.

De estas investigaciones concluyen sus autores, que el agua de La Bourboule es una solución arsenical, coloidal, radioactiva, bactericida, no tóxica, que aumenta de una manera sensible la fagositosis y que en virtud de sus caracteres especiales puede ser inyectada en la sangre.
Todos estos descubrimientos, que han venido a comprobar la utilidad indiscutible de las aguas medicinales, justificada ya por la populosa clientela de las estaciones hidrominerales del extranjero, han complicado también el problema de la terapéutica termal. Las aguas minerales no son ya simples soluciones salinas, arnicales o sulfurosas y son una materia médica mineral viva, que hay que saber dosificar como los alcaloides del opio, son instrumentos que el médico debe saber manejar y que exigen las mayores precauciones. El Profesor Landouzy, con el dón de consición que lo caracteriza dice a este respecto: «La manera de dar una cosa vale tanto como lo que se da.»

Por mi parte, al atender al llamamiento de la Junta Organizadora, convicto y confeso de mi incompetencia en materia tan compleja, declaro que no es mi propósito hacer la propaganda de las aguas minerales del extranjero, sino secundar al justificado anhelo de dicha junta de estudiar nuestros manantiales, pues seríamos muy culpables si por indiferencia dejáramos de aprovecharnos de nuestro patrimonio nacional, continuando tributarios en todo el extranjero, sabiendo que las naciones que no sacan partido de sus riquezas, son naciones condenadas a perecer en manos de la codicia envidiosa de otras más poderosas.

Da tristeza registrar nuestra pobre bibliografía hidrológica; sin embargo, los pocos estudios que existen sobre este asunto, a la par que honran a sus autores, honran también a la hidrología colombiana. En verdad, las importantes tesis de los doctores Diego Sánchez y Víctor Peñuela Rodríguez, nos han presentado en Guane, Tabio, Tocaima, Quetame, Choachí, Aposento, Guatavita, Zipaquirá y Paipa, fuentes medicinales de indiscutible utilidad que, con instalaciones modernas rivalizarían con sus similares de Europa.

¿A qué se deberá el atraso de la hidrología en Colombia? A la laguna que existe en nuestra enseñanza oficial por la cual los nuevos prácticos abandonan la Facultad sin conocer suficientemente la importancia de la terapéutica termal. En la época presente la hidrología es una ciencia que merece tener un sitio en la enseñanza y que debe ocupar una situación autónoma igual al de la electrotecmia o la bacteriología, 
a las cuales se les ha destinado en estos últimos años institutos especiales.

Si queremos aprovecharnos de las maravillosas riquezas termales y climatológicas que encierra nuestro país, si queremos obtener de nuestras aguas minerales todas las ventajas que pueden suministrarnos, es preciso secundar las iniciativas privadas con la creación de un centro científico en donde pueda hacerse el estudio de las aguas de un modo metódico con los elementos especiales para estas investigaciones. Veremos entonces desarrollarse en nuestro país hermosas estaciones termales como las de Francia y Alemania.

Mi óbolo para la hidrología colombiana se seduce ahora, por la premura del tiempo, a presentar al Cuerpo Médico las Aguas medicinales de San Lorenzo. Mantengo la denominación de aguas medicinales. Ateniéndome solamente los benéficos resultados a que debe su reputación regional para el tratamiento del reumatismo crónico, y las dermatosis sifílicas y pruriginosas, pues no pudiendo investigarles por el momento su radioactividad o los fermentos metálicos que puedan explicarnos sus influencias terapéuticas, debemos ganar tiempo contentándonos con las indicaciones del empirismo confirmadas por el análisis químico.

Hé aquí el análisis químico practicado por el doctor Eduardo Lleras Codazzi:

Sulfato de calcio 0.072 por litro.

Sulfato de magnesia 0.021

Cloruro de sodio huellas.

Sales amoniacales

id.

Nitritosíd.

Nitratos, cantidad apreciable.

Estas aguas, consideradas en la localidad como sulfurosas porque despiden un ligero olor a hidrógeno sulfurado, son límpidas y no tienen sabor particular. Su temperatura es de $27^{\circ} \mathrm{C}$.

Por su mineralización pueden clasificarse entre las sulfatadas cálcicas magnesianas débiles. Tienen algunas analogías a las aguas sulfatadas cálcicas de
Bagneres de Bigorre en los Altos Pirineos, cuyas indicaciones son para el neuroartritismo y sus manifestaciones reumatismales y nerviosas y también para ciertas afecciones ginecológicas dismenorrea dolorosa, prurito vulvar, neuralgias utero-ovarianas, etc. El tratamiento es de tres a cuatro semanas, en baños.

Empleadas al interior serían útiles para la litiasis renal y el catarro vesical. Según Rotureau, las aguas sulfatadas cálcicas tienen una acción fisiológica muy marcada sobre el aparato genital, al cual levantarían la tonicidad funcional y orgánica. De aquí su indicación en la espermatorrea, la esterilidad y la incontinencia de orina en los niños.

La acción benéfica de estas aguas para el tratamiento del reumatismo crónico está bien reconocida en toda la región, personas de la localidad citan numerosos casos de enfermos que han llegado en tal extremo de invalidez que han tenido que hacerse conducir en silla a la fuente, y que después de tres días de baños han sido capaces, por su mejoría, de ir por sus propios pies.

San Lorenzo es una población floreciente del Departamento del Tolima; debe su prosperidad al ferrocarril, siendo a su vez una de las estaciones de más movimiento. La línea férrea, al separarse del río Magdalena en Beltrán, se dirige hacia la cordillera hasta dicha población, y luégo sigue paralelamente a aquélla hasta Honda.

Su altura, a 284 metros sobre el nivel del mar, su clima caliente, seco y uniforme, son muy convenientes para los que sufran del corazón o de los riñones. Tiene, por añadidura, un baño delicioso en el río Lagunilla.

\section{Conclusiones}

1. ${ }^{a}$ En todos los tiempos se han servido los hombres de ciertas aguas para el tratamiento de algunas enfermedades, obteniendo buenos resultados de su uso.

2. ${ }^{a}$ Los progresos de la química y de sus métodos de análisis; los descubrimientos de Curie, de Moreu, de Leduc, de Gastou, etc., han sacado la terapéutica 
termal de su estado de empirismo y le han dado a la hidrología el alto rango científico que hoy ocupa.

\section{3. ${ }^{a}$ Las tesis de los doctores Diego Sánchez y Víctor} Peñuela Rodríguez han dado a conocer importantes aguas medicinales del país.

\section{Para sacar a la hidrología del atraso en que se} encuentra en Colombia y dar a conocer a los nuevos prácticos la importancia de la terapéutica hidromineral, se hace necesario darle el puesto que se merece en la enseñanza oficial.

5. a Siendo la explotación de las aguas minerales una industria útil a la terapéutica y a la riqueza nacional, se hace preciso la creación de un centro científico con los elementos especiales para el estudio de esta fuente de riqueza descuidada.

6. Existe en San Lorenzo, en el Departamento del Tolima, una agua medicinal sulfatada cálcica débil, reconocida como muy benéfica para el tratamiento del reumatismo crónico y las dermatosis sifilicas y pruriginosas.

\section{COMENTARIO}

\section{Oscar Eduardo Mendoza MD*}

Es una experiencia única tener la oportunidad de comentar un artículo escrito hace un siglo, siendo aún más agradable poder realizar un seguimiento histórico de los detalles relatados por el autor. Resalta que el deseo de conocimiento y el potencial crítico de los médicos de esa época son incomparables, pues es evidente la capacidad de investigar elementos que realizaban tratamientos de enfermedades buscando una explicación fehaciente de los hechos.

* Médico especialista en Patología, Hospital de San José, Instructor Asistente, Fundación Universitaria de Ciencias de la Salud, Bogotá DC. Colombia
El Dr. Adriano Perdomo describe con detalle las virtudes y características de un manantial ubicado en un caserío del Tolima llamado "San Lorenzo", el cual a pesar de que en la actualidad no aparece en ningún mapa de dicho departamento, es fácil de ubicar debido a las referencias brindadas al final del escrito donde describe la localización del sitio y habla del río Lagunilla; el mismo que es conocido debido a una de las tragedias más grandes que ha envuelto a nuestro país. Y es precisamente realizando una búsqueda en los anales de nuestra historia que podemos determinar que el lugar descrito es el antiguo Armero, cuyo nombre fue inicialmente San Lorenzo al momento de su fundación en 1895, cambiándose en 1930 al conocido por nosotros en honor al mártir José León Armero.

Además, ahondando un poco más en los registros históricos, el manantial detallado por el autor fue convertido en un balneario dos años después de la publicación del artículo en mención, siendo conocido hasta la fecha del desastre como "balneario Tívoli" o "piscina Tívoli"; nombre tal vez inspirado en las famosas termales de Tívoli de Italia, que ya contaban desde aquellos días con el gran prestigio medicinal que aún conservan. El balneario se encontraba dentro del casco urbano del municipio y constaba de varias piscinas rústicas con diversos tamaños y profundidades que eran visitadas hasta el momento de la avalancha que borró del mapa a una de las poblaciones más pujantes del Tolima.

En la actualidad algunos conocedores del antiguo Armero afirman que aún brotan las aguas descritas en medio de las ruinas, siendo el único vestigio del balneario medicinal que existía en dicho lugar, que se hizo famoso para el tratamiento de diversas afecciones de la piel y articulares en el Congreso Médico llevado a cabo en enero de 1913 gracias a la exposición realizada por el Dr. Perdomo. Vale la pena además que durante ese Congreso fue elevada la propuesta del mismo autor para crear la Cruz Roja Colombiana, de la cual es reconocido como Fundador por tal gestión.

Volviendo al tema médico del escrito, se describen con claridad las indicaciones terapéuticas de las Aguas medicinales de San Lorenzo, las cuales podrían atribuirse a sus dos principales componentes, el sulfato de magnesio y el sulfato de calcio. El primero de éstos es 
reconocido en la actualidad por su alta acción a nivel muscular debido a su efecto directo sobre las concentraciones de calcio a nivel del sarcoplasma, por lo que está indicado en la preeclampsia y como inhibidor del trabajo de parto, lo cual nos hace deducir con facilidad que puede tener efectos benéficos en la "dismenorrea dolorosa" y en las "neuralgias utero-ovarianas" descritas por el autor, sin contar con las alteraciones musculoesqueléticas que también enumera.

Además, la riqueza en azufre de las aguas es benéfica para el tratamiento de diversas afecciones dermatológicas debido a que su forma reducida tiene capacidad queratoplástica y la oxidada, queratolítica; por otra parte se ha demostrado su absorción cutánea y su acción vascular con obvia influencia en los cuadros donde el edema y el prurito priman.

La balneoterapia fue muy importante para la medicina a finales del siglo XIX, debido a lo limitado de la terapéutica, sirviendo de tratamiento para diversas patologías que no mostraban mejoría significativa con los manejos existentes en aquellos días. Fue tal su auge que en esa época asistir a los balnearios, que crecieron por toda Europa, era signo de buen nivel social, lo cual se aplicó con muchas limitaciones en nuestro medio a inicios del siglo pasado. Poco a poco la práctica fue entrando en desuso hasta que en la década de los ochenta resurgió a nivel mundial.

Es tal el reconocimiento que se ha brindado a la capacidad curativa de los baños termales que en la actualidad existen en nuestro país complejos turísticos dedicados a los baños en aguas termales, como sucede en Santa Rosa de Cabal, Pozo Azul, la Quinta, El Rancho, Tabio y El Otoño, entre otros. Estos también son reconocidos por sus capacidades curativas y por lo hermoso de los paisajes que los rodean, siendo sitios frecuentados por miles de personas todos los años con fines medicinales y recreativos. Resalta además el hecho de la aparición de estudios fisicoquímicos serios, nacionales e internacionales, que nos detallan las características de dichos balnearios, los cuales han sido presentados en diversos ámbitos científicos apoyando su uso en patologías como las originalmente descritas en el artículo comentado y en algunos cuadros que requieren especial atención en el campo de la rehabilitación. Sin embargo, la mayoría en los mismos no cuenta con rigurosidad científica para poder determinar con certeza lo efectivo de su acción terapéutica. 